\title{
Physiological Response to Exercise in Children with Lung or Heart Disease
}

\author{
S. GODFREY \\ From the Department of Paediatrics, Institute of Diseases of the Chest, and Brompton Hospital
}

\begin{abstract}
Godfrey, S. (1970). Archives of Disease in Childhood, 45, 534. Physiological response to exercise in children with lung or heart disease. The technique of exercise testing in children with lung or heart disease is briefly described and the results of such studies in 5 illustrative cases are discussed in detail, each child being compared with a matched control. The tests enable detailed cardiorespiratory data to be obtained quite simply using arterialized ear-lobe blood, and a rebreathing method for mixed venous $\mathrm{PCO}_{2}$. The practical value of exercise testing in determining the nature and severity of disease processes is described and its special role in confirming normality in the absence of significant disease is discussed.
\end{abstract}

The study of the physiological response to exercise has advantages over more conventional diagnostic techniques at rest, because man is an animal designed for considerable athletic activity and the commonest symptom of disease of the lungs or heart is inability to take normal amounts of exercise. To study the patient's response to exercise investigates the symptom and tests the 'machine' under load rather than just idling - a sound mechanical principle. At rest, studies of ventilation and gas exchange are notoriously unreliable because it is difficult to get a truly resting steady state without considerable inconvenience, and the measurements require a very high degree of instrumental accuracy. It is much easier and quicker to attain a steady state during exercise, and external or emotional influences are much less of a problem. Moreover, the measurements allow for much more latitude in the analyses.

The problem with exercise testing has always been one of technique especially in children, where certain standard adult procedures are unacceptable. These include arterial and right heart catheterization in order to obtain cardiac output. However, techniques were developed in adults for measuring mixed venous $\mathrm{PCO}_{2}$ by a rebreathing method during exercise (Jones et al., 1967), and for estimating cardiac output and dead-space without directly measuring arterial $\mathrm{PCO}_{2}$ (Jones et al., 1966;

Received 10 February 1970.
Higgs et al., 1967). Equations have also been developed for calculating the rise in blood lactate (Clode and Campbell, 1969). These techniques have recently been used in children (Gadhoke and Jones, 1969), and their application has been greatly facilitated by use of a digital computer program (S. Godfrey, in preparation). A simple method of obtaining arterialized blood from the ear-lobe during exercise has also been developed (S. Godfrey et al., in preparation) which renders such studies more valuable.

The present paper attempts to show the types of disturbance encountered in children with lung or heart disease, who have exercised using these techniques. One patient from each of several well-defined groups is presented to illustrate the points.

\section{Methods}

The methods used in these studies will be fully described later and will only be summarized here. All subjects performed two types of exercise seated on a cycle ergometer (Lode).

(a) Progressive exercise. The subject breathed through a low resistance, low dead-space (53 $\mathrm{ml}$.) circuit, inspired ventilation being monitored continuously by means of a gas meter (Parkinson-Cowan C.D.4), and the electrocardiogram was recorded together with other data on a chart recorder (Mingograf 81). Every minute the work load on the cycle was increased by an increment which depended roughly on the size of the 
subject. These increments were 10 watts (W) for children under $120 \mathrm{~cm}$. in height, $15 \mathrm{~W}$ for children between 120 and $150 \mathrm{~cm}$., and $20 \mathrm{~W}$ for children over $150 \mathrm{~cm}$. The subject continued in this way until unable to go on, though the option was always open to the operator to terminate the study earlier if he thought it necessary.

(b) Steady state exercise. After a rest of at least 30 minutes, the subject performed steady state exercise at one-third and two-thirds of the maximum work load achieved in the progressive exercise test. During the initial rest period the subject's ear was prepared with vasodilator cream (Trafuril), and a puncture was made in the lobe which was kept covered by a swab soaked in warm heparinized saline. Expired gas and ear-lobe blood were collected and the mixed venous $\mathrm{PCO}_{2}$ was determined by rebreathing during this rest period, mainly to familiarize the child with the techniques.

Two levels of steady state exercise were then performed. The presence of a steady state was accepted when pulse, ventilation, and mixed expired $\mathrm{O}_{2}$ and $\mathrm{CO}_{2}$ concentration were all steady. This usually occurred after $2 \frac{1}{2}$ minutes of exercise. Expired gas was then collected in a Tissot spirometer over approximately 1 minute, and subsequently analysed for $\mathrm{CO}_{2}$ and $\mathrm{O}_{2}$ using an infrared $\mathrm{CO}_{2}$ analyser (URAS-4) and a paramagnetic $\mathrm{O}_{2}$ analyser (Servomex OA150). Arterialized ear-lobe blood was collected in polyethylene tubes and analysed immediately for $\mathrm{Po}_{2}$ and $\mathrm{PCO}_{2}$ using microelectrodes (Eschweiler). The mixed venous $\mathbf{P C O}_{2}$ was measured by the rebreathing method using a set of cylinders containing different concentrations of $\mathrm{CO}_{2}$ in $\mathrm{O}_{2}$ to prime the rebreathing bag. A satisfactory record was always obtained with one or two attempts. The uncorrected plateau value was used as mixed venous $\mathrm{PCO}_{2}$ in all instances, unless the plateau was technically unsatisfactory (Jones et al., 1967) in which case the correction described by Denison et al. (1969) was used. End-tidal $\mathrm{PCO}_{2}$ was sampled at the mouth during gas collection and rebreathing. As soon as a satisfactory rebreathing plateau had been obtained, the work load was increased to the second level and the whole procedure repeated.

All analytical apparatus was calibrated for each measurement with gases analysed in duplicate by a Lloyd-Haldane apparatus. All calculations were per- formed by a digital computer using the equations mentioned in the Introduction. Resting blood lactate was assumed to be $1.0 \mathrm{mN}$.

\section{Results}

In order to illustrate the use of exercise tests, the results of studies on 5 young patients are presented. For comparison each patient has been paired with a control matched as closely as possible for size from a series of normal children studied in this laboratory by the same methods. In most cases the patients were relatively small for their age as a result of their disease, and hence the controls were relatively younger. The basic details and spirometry of the 5 pairs are given in Table $I$, the results of progressive exercise tests in Table II, and the results of steady state exercise at the highest level achieved in Table III. Each pair will now be discussed separately.

Pair 1: cystic fibrosis. The patient and control were of closely similar size but the forced expiratory volume in one second $\left(\mathrm{FEV}_{1.0}\right)$ and forced vital capacity (FVC) were somewhat reduced in the patient (Table I). In the progressive test the patient achieved a similar highest work load $\left(W_{\max }\right)$ to the control with a similar pulse $\left(P_{\max }\right)$ and a moderate increase in ventilation $\left(\mathrm{V}_{\max }\right)$ as shown in Table II. The only real difference in the steady state test (Table III) between the pair of subjects was the obvious increase in physiological dead-space in the patient. Though venous admixture in the patient was almost normal on exercise, this was a conspicuous improvement on the resting figure (not shown) which was $15 \cdot 4 \%$. It should be noted that the total ventilation in the patient was high because of the large dead-space, while that of the control was relatively high because of alveolar hyperventilation (low arterial $\mathrm{PCO}_{2}$ ) probably provoked by lactic acidosis. The changes in the patient are characteristic of mild cystic fibrosis. At a later stage of the disease the dead-space would be larger, venous admixture much increased, and working capacity severely restricted.

TABLE I

Physical Characteristics and Spirometry of Patients and Controls

\begin{tabular}{|c|c|c|c|c|c|c|c|c|c|c|}
\hline \multirow[t]{2}{*}{ Pair No. } & \multicolumn{2}{|c|}{1} & \multicolumn{2}{|c|}{2} & \multicolumn{2}{|c|}{3} & \multicolumn{2}{|c|}{4} & \multicolumn{2}{|c|}{5} \\
\hline & Patient & Control & Patient & Control & Patient & Control & Patient & Control & Patient & Control \\
\hline $\begin{array}{l}\text { Sex } \\
\text { Age (yr.) } \\
\text { Height (cm.) } \\
\text { Weight (kg.) } \\
\text { Surface area }\left(\mathrm{M.}^{2}\right) \\
\text { FEV }_{1 \cdot 0}(1) \\
\text { FVC (1) }\end{array}$ & $\begin{array}{c}F \\
10 \cdot 0 \\
138 \\
27 \cdot 4 \\
1 \cdot 07 \\
1 \cdot 32 \\
1 \cdot 54\end{array}$ & $\begin{array}{c}F \\
9 \cdot 5 \\
138 \\
29 \cdot 8 \\
1 \cdot 08 \\
1 \cdot 70 \\
1 \cdot 95\end{array}$ & $\begin{array}{c}M \\
12 \cdot 7 \\
139 \\
31 \cdot 5 \\
1 \cdot 11 \\
0 \cdot 61 \\
1 \cdot 54\end{array}$ & $\begin{array}{l}M \\
9 \cdot 8 \\
139 \\
29 \cdot 6 \\
1 \cdot 09 \\
2 \cdot 24 \\
2 \cdot 47\end{array}$ & $\begin{array}{c}M \\
10 \cdot 5 \\
133 \\
26 \cdot 5 \\
1 \cdot 01 \\
1 \cdot 65 \\
1 \cdot 82\end{array}$ & $\begin{array}{c}M \\
8 \cdot 5 \\
133 \\
28 \cdot 9 \\
1 \cdot 04 \\
1 \cdot 87 \\
2 \cdot 09\end{array}$ & $\begin{array}{c}F \\
10 \cdot 9 \\
143 \\
32 \cdot 7 \\
1 \cdot 17 \\
1 \cdot 90 \\
2 \cdot 10\end{array}$ & $\begin{array}{c}F \\
10 \cdot 7 \\
143 \\
32 \cdot 8 \\
1 \cdot 17 \\
1 \cdot 96 \\
2 \cdot 24\end{array}$ & $\begin{array}{c}M \\
14 \cdot 0 \\
166 \\
49 \cdot 8 \\
1 \cdot 55 \\
-\end{array}$ & $\begin{array}{c}M \\
14 \cdot 4 \\
167 \\
49 \cdot 5 \\
1 \cdot 56 \\
2 \cdot 92 \\
3 \cdot 63\end{array}$ \\
\hline
\end{tabular}


TABLE II

Results of Progressive Exercise Tests

\begin{tabular}{|c|c|c|c|c|c|c|c|c|c|c|}
\hline \multirow[t]{2}{*}{ Pair No. } & \multicolumn{2}{|c|}{1} & \multicolumn{2}{|c|}{2} & \multicolumn{2}{|c|}{3} & \multicolumn{2}{|c|}{4} & \multicolumn{2}{|c|}{5} \\
\hline & Patient & Control & Patient & Control & Patient & Control & Patient & Control & Patient & Control \\
\hline $\begin{array}{l}\text { Highest work load completed } \\
\text { (W) } \\
\text { Pulse at highest work load } \\
\text { (beats/min.) } \\
\text { Ventilation at highest work } \\
\text { load (1./min.) }\end{array}$ & $\begin{array}{r}75 \\
205 \\
51 \cdot 5\end{array}$ & $\begin{array}{r}75 \\
206 \\
45 \cdot 7\end{array}$ & $\begin{array}{r}75 \\
200 \\
30 \cdot 4\end{array}$ & $\begin{array}{r}120 \\
193 \\
50 \cdot 7\end{array}$ & $\begin{array}{r}90 \\
201 \\
50 \cdot 0\end{array}$ & $\begin{array}{r}90 \\
190 \\
58 \cdot 0\end{array}$ & $\begin{array}{r}60 \\
191 \\
47 \cdot 2\end{array}$ & $\begin{array}{r}75 \\
194 \\
29 \cdot 8\end{array}$ & $\begin{array}{l}200 \\
192 \\
71 \cdot 2\end{array}$ & $\begin{array}{r}220 \\
189 \\
104 \cdot 0\end{array}$ \\
\hline
\end{tabular}

Pair 2: pulmonary hypoplasia. The patient in this pair had suffered a severe bronchiolitis in infancy and his lungs had probably never been able to develop properly thereafter. He was small and was matched with a control nearly 3 years younger than himself. Spirometry showed severe airways obstruction (Table I). His effort tolerance was somewhat reduced compared with that of his much younger control. That this was a truly maximal effort is indicated by his $P_{\max }$ which was up to the highest levels usually seen in children. His ventilation $\left(\mathrm{V}_{\max }\right)$ was relatively low even for 75 watts (see control of Pair 1 ).

In the steady state test (Table III) there are a number of gross differences from the control. Simple measurements of ventilation, such as total ventilation, tidal volume, frequency, and gas exchange could be highly misleading alone since they were all normal. However, the blood gases are highly abnormal with increases of mixed venous $\mathrm{PCO}_{2}$ and of arterial $\mathrm{PCO}_{2}$ indicating alveolar hypoventilation, and arterial hypoxia. Dead-space is about twice that of the control. Thus, though total ventilation was normal, alveolar ventilation was very reduced due to a combination of an enlarged dead-space and primary hypoventilation -in order to keep arterial $\mathrm{PCO}_{2}$ normal total ventilation would have needed to be $35.01 . / \mathrm{min}$. The hypoxia was only partly due to alveolar hypoventilation, since venous admixture was considerably increased indicating regions of lung with low ventilation-perfusion ratios. Cardiac output was normal, and though stroke volume was lower than that of the control who had a slower pulse, it was no different from other normal children of similar size (compare the control of Pair 1). This pattern of severe alveolar hypoventilation and ventilationperfusion imbalance has been seen in other children with pulmonary hypoplasia.

Pair 3: multiple lung cysts. The patient was small for his age and was matched with a boy 2 years his junior. In relation to his size his spirometry was only marginally reduced (Table I). The progressive exercise test was entirely normal for his size (Table II), but the steady state test

TABLE III

Results of Steady State Tests

\begin{tabular}{|c|c|c|c|c|c|c|c|c|c|c|}
\hline \multirow[t]{2}{*}{ Pair No. } & \multicolumn{2}{|c|}{1} & \multicolumn{2}{|c|}{2} & \multicolumn{2}{|c|}{3} & \multicolumn{2}{|c|}{4} & \multicolumn{2}{|c|}{5} \\
\hline & Patient & Control & Patient & Control & Patient & Control & Patient & Control & Patient & Control \\
\hline $\begin{array}{l}\text { Work load (W) } \\
\text { Ventilation (l./min.) } \\
\text { Tidal volume (ml.) } \\
\text { Frequency (per min.) } \\
\mathrm{O}_{2} \text { uptake (ml./min.) } \\
\text { Respiratory ratio } \\
\text { Mixed venous } \mathrm{PCO}_{2}(\mathrm{~mm} . \mathrm{Hg}) \\
\text { Arterial } \mathrm{PCO}_{2}(\mathrm{~mm} . \mathrm{Hg}) \\
\left.\text { Arterial } \mathrm{Po}_{2} \text { (mm. } \mathrm{Hg}\right) \\
\text { Arterial saturation }(\%) \\
\text { Dead space (ml.) } \\
\text { Cardiac output (l./min.) } \\
\text { Pulse (per min.) } \\
\text { Stroke volume (ml.) } \\
\text { Venous admixture (\%) } \\
\text { Arterial lactate (mN) }\end{array}$ & $\begin{array}{c}50 \\
34 \cdot 6 \\
639 \\
54 \\
818 \\
0 \cdot 94 \\
54 \cdot 5 \\
37 \cdot 0 \\
83 \cdot 0 \\
96 \cdot 5 \\
250 \\
10 \cdot 0 \\
193 \\
53 \\
5 \cdot 1 \\
1 \cdot 8\end{array}$ & $\begin{array}{c}50 \\
36 \cdot 6 \\
713 \\
51 \\
1020 \\
1 \cdot 14 \\
64 \cdot 9 \\
33 \cdot 7 \\
94 \cdot 0 \\
97 \cdot 0 \\
84 \\
9 \cdot 8 \\
191 \\
51 \\
2 \cdot 3 \\
6 \cdot 3\end{array}$ & $\begin{array}{c}50 \\
24 \cdot 9 \\
598 \\
42 \\
912 \\
1 \cdot 03 \\
80 \cdot 8 \\
56 \cdot 0 \\
62 \cdot 0 \\
91 \cdot 5 \\
190 \\
9 \cdot 7 \\
194 \\
50 \\
14 \cdot 1 \\
5 \cdot 9\end{array}$ & $\begin{array}{c}40 \\
24 \cdot 7 \\
585 \\
42 \\
864 \\
0 \cdot 95 \\
59 \cdot 3 \\
36 \cdot 8 \\
84 \cdot 5 \\
97 \cdot 0 \\
76 \\
9 \cdot 3 \\
138 \\
67 \\
2 \cdot 6 \\
3 \cdot 2\end{array}$ & $\begin{array}{c}60 \\
44 \cdot 0 \\
761 \\
58 \\
987 \\
1 \cdot 18 \\
78 \cdot 0 \\
44 \cdot 5 \\
77 \cdot 5 \\
94 \cdot 9 \\
318 \\
10 \cdot 3 \\
203 \\
51 \\
5 \cdot 4 \\
8 \cdot 6\end{array}$ & $\begin{array}{c}60 \\
37 \cdot 4 \\
702 \\
53 \\
1020 \\
1 \cdot 06 \\
63 \cdot 4 \\
33 \cdot 0 \\
87 \cdot 5 \\
97 \cdot 0 \\
110 \\
9 \cdot 0 \\
184 \\
49 \\
3 \cdot 1 \\
5 \cdot 5\end{array}$ & $\begin{array}{c}20 \\
36 \cdot 9 \\
811 \\
46 \\
600 \\
0 \cdot 96 \\
51 \cdot 8 \\
19 \cdot 0 \\
43 \cdot 0 \\
80 \cdot 5 \\
180 \\
5 \cdot 3 \\
173 \\
31 \\
28 \cdot 8 \\
1 \cdot 8\end{array}$ & $\begin{array}{c}25 \\
17 \cdot 5 \\
530 \\
33 \\
599 \\
0 \cdot 96 \\
56 \cdot 5 \\
37 \cdot 4 \\
95 \cdot 0 \\
97 \cdot 0 \\
74 \\
7 \cdot 5 \\
161 \\
46 \\
1 \cdot 9 \\
1 \cdot 3\end{array}$ & $\begin{array}{c}132 \\
52 \cdot 4 \\
1512 \\
35 \\
2132 \\
0 \cdot 94 \\
73 \cdot 0 \\
37 \cdot 3 \\
77 \cdot 5 \\
96 \cdot 0 \\
130 \\
14 \cdot 4 \\
188 \\
77 \\
2 \cdot 0 \\
4 \cdot 3\end{array}$ & $\begin{array}{c}146 \\
61 \cdot 0 \\
1302 \\
47 \\
2388 \\
0 \cdot 95 \\
74 \cdot 0 \\
38 \cdot 0 \\
93 \cdot 0 \\
97 \cdot 0 \\
142 \\
16 \cdot 5 \\
161 \\
102 \\
1 \cdot 8 \\
1 \cdot 8\end{array}$ \\
\hline
\end{tabular}


brought to light several abnormalities (Table III). Total ventilation was considerably increased but, despite this, alveolar ventilation was still low since arterial $\mathrm{PCO}_{2}$ was raised. As in Pair 2, the increase in total ventilation reflected an increase in deadspace, but another factor here was probably acidosis due to the high lactate indicating excessive anaerobic metabolism. There was some arterial desaturation but venous admixture was only moderately increased. The over-all picture of high ventilationperfusion ratios is similar to that seen in cystic fibrosis as in Pair 1, but the other factor of alveolar hypoventilation is not seen in cystic fibrosis. Cardiac output was normal. The patient had multiple bullae in the right lung visible radiologically but was otherwise well. The pattern of response to exercise is similar in some ways to that seen in adult emphysema (Jones, 1966), but differs in the failure to desaturate significantly on exercise. This probably means less extensive disease.

Pair 4: Eisenmenger's syndrome. The patient and her control were very similar in age, size, and spirometry (Table I). In the progressive test the patient was unable to do as high a level of work and her $V_{\max }$ was very high. In fact ventilation and pulse were excessive at all levels below $\mathbb{W}_{\max }$, which are not shown. She was unable to complete the higher level of work in her steady state test and the results shown in Table III are for the lower level, i.e. one-third of her $W_{\max }$. Total ventilation was double that of the control for an identical level of $\mathrm{O}_{2}$ consumption, and this reflected gross alveolar hyperventilation with a very low arterial $\mathrm{PCO}_{2}$. There was a moderate increase in dead-space, though it is difficult to be accurate at this respiratory frequency and low work level. Cardiac output was very low and stroke volume very small, but this only reflects the volume of blood passing through the lungs. Venous admixtureright-to-left shunt-was grossly excessive, and almost one-third of the blood leaving the left side of the heart came directly from the right. If this is added to the calculated cardiac output, it would give a right ventricular output which was close to normal. The venous admixture at rest was nearly $30 \%$, and on breathing $100 \% \mathrm{O}_{2}$ at rest until all $\mathbf{N}_{2}$ was flushed out of the lungs, the venous admixture only fell to $21 \%$. This confirms that the right-to-left shunt was intracardiac and not due to poor ventilation-perfusion balance in the lungs, and also that $\mathrm{O}_{2}$ is incapable of reducing pulmonary vascular resistance to any real degree. This child had a ventricular septal defect with pulmonary hypertension causing the right-to-left shunt. The alveolar hyperventilation is often seen in other conditions with pulmonary hypertension of noncardiac origin, e.g. pulmonary embolism (Jones and Goodwin, 1965) and is probably of reflex origin.

Pair 5: suspected heart disease. The patient and control were closely matched for size, and though spirometry was unfortunately not performed by the patient his peak expiratory flow rate was measured as $4601 . / \mathrm{min}$. which was normal. His $\mathrm{W}_{\text {max }}$ was one level lower than that of the control (Table II). During steady state exercise at a slightly lower level of work (oxygen consumption $10 \%$ lower), there is no abnormality since the lower cardiac output $(12 \%)$ is proportional to the lower oxygen consumption. Stroke volume is $25 \%$ lower, but this is really due to the remarkably slow pulse of the control subject-the sign of a very fit person. The patient had been suspected of having a cardiomyopathy on the grounds of a systolic murmur and a radiological heart shadow at the upper limit of normal. The results of these exercise tests showed that functionally he was completely normal, making the diagnosis extremely unlikely. Other children with cardiomyopathy who have been studied produce highly abnormal results.

\section{Discussion}

These five pairs of patients serve to illustrate that exercise tests are both practical and informative in even quite young children. In fact we have extended our normal range to include 6-year-old girls and boys (S. Godfrey and C. T. M. Davies, in preparation), which is much younger than the boys studied by Gadhoke and Jones (1969), and a number of 6-year-old patients not presented here have also been studied.

The chief difference between the type of study described here and those done previously on healthy or sick children (Bengtsson, 1956; Duffie and Adams, 1963) has been the measurement of the absolute values of cardiac output, stroke volume, dead-space, and venous admixture. The use of the rebreathing method for mixed venous $\mathrm{PCO}_{2}$ and arterialized ear-lobe blood for $\mathrm{PCO}_{2}$ and $\mathrm{PO}_{2}$ has proved very acceptable to the children, and enabled these important derived values to be calculated. The use of a computer program has rendered the calculations simple, vastly reduced the time taken, and increased the accuracy.

The tests, such as those described, have in fact now become routine in this department. The only contraindications to these types of study are disease which renders the child so ill as to be 
unable to exercise at all, inability to co-operate through lack of intelligence or fear (very rare), and the presence of significant left-to-right shunt which renders the rebreathing method for mixed venous $\mathrm{PCO}_{2}$ invalid. In the latter case a technique is being developed at present to use a fine polyethylene catheter which can be floated into the pulmonary artery quite simply and painlessly from a peripheral venepuncture.

The value of exercise tests is well illustrated by these 5 pairs of patients. The progressive and steady state tests each have uses which render them complementary. The progressive test gives an over-all assessment of physical working capacity, is simple and quick to perform, and can be repeated frequently for follow-up comparisons. It may also give some clues to the likely source of effort intolerance if present. For example the child with cystic fibrosis and an enlarged dead-space (Pair 1) stops work at a lower level than the control with a relatively high ventilation, whereas the child with cardiac disease (Pair 4) had both hyperventilation and tachycardia throughout. However, the progressive test cannot provide any more than crude answers and indeed may even be apparently normal in the presence of considerable disease (Pair 3).

The steady state test has similar uses in children to that in adults (Campbell, 1967). It quantitates any abnormality present and provides certain patterns characteristic of different pathological conditions. Moreover, it can differentiate between superficially similar disturbances. Thus, though total ventilation was increased in the patients from Pairs 1, 3, and 4, dead-space was enlarged in 1 and 3, alveolar hypoventilation was present in 3 and 4 , and right-to-left shunt in 4.

These tests, though very useful in children with heart or lung disease, are also of great value in what may be called respiratory or cardiac 'non-disease'. It has been suggested that the morbidity of cardiac non-disease is greater than that of real disease (Bergman and Stamm, 1967), and one often meets the child with a benign systolic murmur or unimportant shadow on chest $x$-ray who is labelled as having a 'weak heart' or 'weak chest'. A normal performance on exercise in both progressive and steady state tests is probably the best index of functional normality as in the patient of Pair 5, and may be used to reassure patient, parents, and doctors.

Finally, the analysis of effort intolerance in the terms described here enables the physician to provide logical explanations for the symptom which is usually the chief cause of concern.

\section{REFERENCES}

Bengtsson, E. (1956). The working capacity in normal children, evaluated by submaximal exercise on the bicycle ergomete and compared with adults. Acta Medica Scandinavica, 154, 91.

Bergman, A. B., and Stamm, S. J. (1967). The morbidity of cardiac nondisease in schoolchildren. New England fournal of Medicine. 276, 1008.

Campbell, E. J. M. (1967). Exercise tolerance. Scientific Basis of Medicine. Annual Review, 128.

Clode, M., and Campbell, E. J. M. (1969). The relationship between gas exchange and changes in blood lactate concentrations during exercise. Clinical Science, 37, 263.

Denison, D., Edwards, R. H. T., Jones, G., and Pope, H. (1969). Direct and rebreathing estimates of the $\mathrm{O}_{2}$ and $\mathrm{CO}_{2}$ pressures in mixed venous blood. Respiration Physiology, 7, 326.

Duffie, E. R., Jr., and Adams, F. H. (1963). The use of the working capacity test in the evaluation of children with congenital heart disease. Pediatrics, 32, 757.

Gadhoke, S., and Jones, N. L. (1969). The responses to exercise in boys aged 9-15 years. Clinical Science, 37, 789.

Higgs, B. E., Clode, M., McHardy, G. J. R., Jones, N. L., and Campbell, E. J. M. (1967). Changes in ventilation, gas exchange and circulation during exercise in normal subjects. Clinical Science, 32, 329.

Jones, N. L. (1966). Pulmonary gas exchange during exercise in patients with chronic airway obstruction. Clinical Science, 31, 39.

—, Campbell, E. J. M., McHardy, G. J. R., Higgs, B. E., and Clode, M. (1967). The estimation of carbon dioxide pressure of mixed venous blood during exercise. Clinical Science, 32, 311.

- , and Goodwin, J. F. (1965). Respiratory function in pulmonary thromboembolic disorders. British Medicalfournal, $1,1089$.

—, McHardy, G. J. R., Naimark, A., and Campbell, E. J. M. (1966). Physiological dead space and alveolar-arterial gas pressure differences during exercise. Clinical Science, 31, 19.

Correspondence to Dr. S. Godfrey, Institute of Diseases of the Chest, British Postgraduate Medical Federation, Brompton, London S.W.3. 